\title{
FILOSOFIA E LITERATURA: SOBRE O ROMANCE LA NAUSÉE
}

\author{
[ Philosophy and literature: About the novel LA NAUSÉE ]
}

\begin{abstract}
RESUmo: No presente artigo, procuro demonstrar como a filosofia e a literatura fazem parte do conjunto do pensamento de Jean-Paul Sartre. Analisarei trechos do primeiro romance publicado, La nausée, de 1938. O estudo será, sobretudo, dos excertos que remetem aos conceitos de contingência, gratuidade e facticidade. Pretendo mostrar como a máxima do existencialismo, a saber, $a$ existência precede a essência, já se encontra presente nesta obra cuja escrita foi iniciada no início da década de 1930 e, consequentemente, as implicações teóricas de se expressar verdades metafísicas pela via da ficção.
\end{abstract}

Palavras-chave: Contingência; Facticidade; Existencialismo
Abstract: In this article, I try to demonstrate how philosophy and literature are part of JeanPaul Sartre's thinking. I will analyze excerpts from the first published novel, La nausée (1938). The study will be about excerpts that refers to the concepts: contingency, gratuity and facticity. I intend to show how the maxim of existentialism, the existence precedes the essence, is already present in this work, whose writing started in the early 1930s and consequently what are the theoretical implications of expressing metaphysical truths through fiction.

KEYWORDS: Contingency; Facticity;

[...] il faut donc écrire la vie d'une théorie comme on écrit celle d'une passion.

Paul Valery

\section{INTRODUÇÃo}

Aênese de La nausée remonta a 1931: são três principais obras que darão o ponto de partida do primeiro romance de Jean-Paul Sartre ${ }^{2}$, a saber, um poema intitulado L'arbre, uma peça chamada Épiméthée e um volume do ensaio La légende de la vérité. Sartre escrevia, neste momento, o que ele chamou de factum sur la Contingence ${ }^{3}$. Uma segunda versão é retrabalhada durante a estadia de Sartre em Berlim para estudar a fenomenologia de Husserl no período letivo de 1933-1934. A elaboração de uma terceira versão é interrompida por ocasião da escrita de L'imagination e é no verão de 1936 que o manuscrito é finalizado. Intitulado Melancholia em referência à

* Doutora em Filosofia pela Universidade Estadual de Campinas-UNICAMP. Pós-doutoranda em Filosofia pela Universidade Federal de São Carlos-UFSCar, Bolsista FAPESP - Fundação de Amparo à Pesquisa do Estado de São Paulo.m@ilto: luizahilgert@hotmail.com 
gravura Melencolia I, de Albrecht Dürer, a obra é publicada na primavera de 1938 e torna Sartre conhecido no meio literário e intelectual parisiense.

Segundo Contat e Rybalka (1970), as reflexões empreendidas em La nausée resultam, em alguma medida, de marcantes situações e experiências, como os anos de docência em Havre, a depressão profunda em consequência do uso de mescalina, a

26 escalada do fascismo e o triunfo do nazismo na Alemanha. São bem conhecidas as histórias de que é o próprio Gaston Gallimard quem sugere a mudança do título de Melancholia para La nausée e de que o manuscrito fora recusado pela editora Gallimard quando enviado por Paul Nizan e aceito no primeiro semestre de 1937, quando recomendado por Charles Dullin e Pierre Bost. Gallimard afirma que a recusa se deu em razão de um mal-entendido: "il aurait cru que Sartre souhaitait que Melancholia parût dans la revue 4 , ce que la longueur du texte rendait impossible" (IDT, 2001, p. 49). Há dados, contudo, que sugerem que a editora Gallimard não sedia facilmente às influências e recomendações e apontam como possível fator na decisão favorável à publicação o envio de alguns dos contos que figurarão na coletânea Le mur.

Le 27 avril 1937, à l'instigation de Beauvoir, de Pierre Guille et de JacquesLaurent Bost, le jeune frère de Pierre, Sartre se decide à écrire à Paulhan pour lui soumettre quelques nouvelles qu'il vient d'écrire: Le mur, Dépaysement, Érostrate. Il obtient un rendez-vous pour le 30 abril. (IDT, 2001, p. 49).

Ainda segundo Idt, a imprensa recebeu a Sartre e as suas obras como a uma promessa de grande escritor: "avec un large consensus, elle voit dans La nausée le début d'une grande œuvre, puis dans Le mur une confirmation de ses predictions. A quelques rares exceptions aisement explicables, les jugements des critiques ne refletent guere les divisions ideologiques où ils s'expriment [...]" (2001, pp 57-58). Albert Camus, por exemplo, escreveu uma resenha de La nausée afirmando que via Sartre como uma grande promessa para a literatura e esperava com impaciência as obras e os ensinamentos futuros ${ }^{5}$. La nausée conta a história de um homem que se analisa e, ao fazê-lo, observa o seu entorno e, por meio dessa análise encontra a absurdidade, tema caro a Camus:

En lui-même à vrai dire, le livre n'a pas figure de roman, mais plutôt de monologue. Un homme juge sa vie et par là se juge. Je veux dire qu'il analyse sa présence au monde, le fait qu'il remue ses doigts et mange à heure fixe - et ce qu'il trouve au fond de l'acte le plus élémentaire, c'est son absurdité fondamentale. (CAMUS, 1939, p. 51).

O tema central do romance é a descoberta da contingência. Segundo Simone de Beauvoir ${ }^{6}$, foi contrastando as imagens reais com as imagens cinematográficas que Sartre foi atingindo pela noção de acaso (l'hasard) ao perceber-se que os objetos em um filme têm um papel precisamente ligado ao personagem, determinado anteriormente, enquanto que na realidade os objetos existem casualmente. O fato é confirmado por Sartre:

Je sais que l'idée de contingence est venue de la comparaison qui s'est établie spontanément chez moi entre le paysage dans un film et le paysage dans la réalité. Le paysage d'un film, le metteur en scène s'est arrangé pour qu'il ait une certaine unité et un rapport précis avec les sentiments des personnages. Tandis que le paysage de la réalité n'a pas d'unité. Il a une unité de hasard et ça m'avait beaucoup frappé. [...] Et alors, à cette époque-là ${ }^{7}$ et jusqu'à deux ans avant $L a$ nausée, je pensais que l'art n'était pas l'imaginaire mais que c'était bel et bien la saisie d'essences. Une œuvre d'art était donc la création presque d'une essence. Elle faisait surgir dans le monde une essence pareille aux autres essences. Et elle avait un caractère d'unité profonde, de necessité profonde, tandis que la vie c'était la contingence. (SARTRE, citado por CONTAT e RYBALKA, 1981, pp. 
1698-1699).

Os temas da descoberta da contingência, do desamparo, da gratuidade e da facticidade serão teorizados filosoficamente nos anos 1940 no ensaio L'être et le néant e na conferência L'existentialisme est un humanisme, no entanto a revelação da faciticidade por meio da consciência de corpo, a gratuidade da existência, a contingência, etc. são privilegiados em La nausée. Pretendo mostrar, no presente artigo, como problemas filosóficos e concepções teóricas são tratados nas obras ficcionais e as implicações teóricas de se expressar verdades metafísicas pela via da ficção.

\section{EXPRIMIR IDEIAS DE UMA FORMA BELA: DUPLICAR A ESCRITA}

A relação entre filosofia e literatura em Sartre é tema valioso de estudos desde as primeiras publicações do autor. Quase todos os pesquisadores da filosofia de Sartre iniciam seus estudos pelas obras teórico-filosóficas e, com o tempo, percebem a relevância das obras ficcionais e a necessidade de também conhecê-las para compreender o conjunto da obra do pensamento do autor. Na História da Filosofia, poesia, literatura, dramaturgia, bem como outras formas de escrita para além dos tratados e ensaios, andaram lado a lado, como no caso de Parmênides com seus poemas, Platão com os diálogos, Nietzsche e os aforismos, entre outros. O caso de Sartre é muito particular e especial porque filosofia e literatura ocuparam diferentes lugares ao longo da vida do autor. Sartre se considera, especialmente até a publicação de L'être et le néant, antes de tudo um escritor de prosa: "J'ai toujous été écrivain d'abord, et puis philosophe, c'est venu comme ça" $\left(1977\right.$, p. 41) ${ }^{8}$.

Pouco depois da publicação de La nausée, Sartre concede entrevista a Claudine Chonez sobre fenomenologia, projetos futuros e a obra que acabara de vir à luz, na qual declara:

J'aurais rêvé de n'exprimer mes idées que dans une forme belle - je veux dire dans l'oeuvre d'art, roman ou nouvelle. Mais je me suis aperçu que c'était impossible. Il y a des choses trop techniques, qui exigent un vocabulaire purement philosophique. Aussi je me vois obligé de doubler, pour ainsi dire, chaque roman d'un essai. Ainsi, en même temps que La nausée, j'écrivais $L a$ psiché, ouvrage qui va bientôt paraître et qui traite de la psychologie du point de vue phénomélogique. (SARTRE, citado por CONTAT e RYBALKA, 1971, p. 65).

A obrigação de duplicar cada tema com um romance e um ensaio nos permite pensar a interconexão entre as obras ficcionais e teóricas no conjunto do pensamento de Sartre. Se essa concepção de duplicação da escrita irá manter-se ao longo da carreira do intelectual é tema para investigações futuras; o ponto importante aqui é como, neste momento da publicação do primeiro romance de Sartre e que antecede por pouco a primeira monumental obra de filosofia do francês, a relação entre filosofia e literatura é concebida: a intenção de exprimir teorias e ideias de forma bela, ou ficcional se preferirmos, exige também - em razão da complexidade técnica do tema - um ensaio teórico filosófico. Isso nos leva a duvidar da interpretação historicamente consolidada entre os estudiosos do pensamento de Sartre - e método generalizado entre aqueles e aquelas que se interessam pelas relações entre arte e filosofia, sobretudo entre literatura e filosofia - de aproximar filosofia e literatura entendendo esta como exemplificação e ilustração para aquela, uma vez que o que seria exemplificação veio antes das ideias. Não me deterei sobre o tema porque já escrevi sobre em outras oportunidades, no entanto, de modo bastante breve, julgo relevante resumir alguns pontos.

Destaco duas vertentes interpretativas no que se refere a conceber a relação entre Literatura e Filosofia: i.) uma que considera o romance, o conto e o teatro como 
metáforas e exemplos ilustrativos às teorias filosóficas de Sartre, recursos didáticos para fazer chegar ao grande público os conceitos abstratos; ii.) e outra que toma cada obra como um fim em si mesma sem que haja hierarquia entre filosofia e literatura. Eu me filio à segunda, isto é, àquela que compreende que no pensamento de Sartre tanto filosofia quanto literatura são objetos de pesquisa. Na minha tese de doutorado ${ }^{9}$ e em um artigo recentemente publicado na revista Analytica ${ }^{10}$ discuto de modo um pouco mais detalhado essas duas leituras e suas consequências, mas em resumo, defendo que os diferentes gêneros de escrita não representam limites à expressividade teórica do autor, tampouco podemos estabelecer a dependência da literatura: ao mesmo tempo que Sartre faz uma filosofia dramática, a ficção exige metafísica. Consequentemente, do ponto de vista do método para o pesquisador e a pesquisadora, se torna valioso estudar o pensamento sartriano a partir da ideia de conjunto da obra, isto é, considerando a totalidade e a integralidade ao mesmo tempo de cada obra, de cada modo de manifestação expressiva e de cada momento ou fase do filósofo, para compreender o pensamento no seu movimento dinâmico.

Como vimos, a gênese de La nausée é compartilhada com pesquisas e escritos de filosofia sobre o tema da psiqué, da consciência, da imaginação e da fenomenologia. A escrita do romance é concomitante ao estudo da fenomenologia husserliana:

\section{Contat: Et en même temps vous travailliez à La nausée ?}

Sartre: Oui, alors, à Berlin, le matin je lisais Husserl, et j'allais déjeuner où je voulais, j'allais me balader dans la ville, c'était l'aventure. Et puis je rentrais vers cinq heures et demie, après avoir eu bien des aventures. (ASTRUC e CONTAT, 1977, p. 44)

Como esses, há vários elementos que contrapõem a interpretação de que Sartre traduzia em belas imagens literárias seus conceitos complexos e difíceis, como se $L a$ nausée fosse um artifício pedagógico para proporcionar a compreensão dos conceitos de contingência, facticidade, gratuidade, etc. e ilustrassem o caminho percorrido por Roquentin na aventura da existência, coisa que poderia, de modo assemelhado às parábolas e fábulas, servir de modelo para que agentes de má-fé perscrutassem o ser em busca de descobertas filosóficas. Contat e Rybalka supõem o movimento inverso: que Sartre inventa uma filosofia para justificar teoricamente as imagens: "Il nous apparaît cependant aujourd'hui que les images e métaphores de l'oeuvre ne sont pas toujours là pour illustrer un système mais qu'au contraire Sartre invente une philosophie pour unifier ces images et rendre compte de ses propres obsessions" (CONTAT e RYBALKA, 1970, p. 63).

Contat e Rybalka propõem que Sartre inventa uma filosofia que unifica a ficção e, assim, participam da escalada controversa que hierarquiza a filosofia sobre a literatura na medida em que o sustento dessa afirmação reside na crença de que as obras da imaginação não contêm por si uma metafísica, mas caberia à filosofia dar sentido, dar razão, organizar, ordenar aquilo que na literatura são imagens e metáforas bastante confusas oriundas de obsessões e equívocos teóricos cuja tarefa de Sartre-filósofo seria a de criar uma filosofia, engendrar um sistema que desse conta de racionalizar, de pensar, aquilo que a literatura e o Sartre-escritor não estão aptos a fazer.

\section{FOLHA SEM DATA: INTROdUÇ̃̃o À PESQUiSA}

Antoine Roquentin é um intelectual, um pesquisador acadêmico, um aventureiro. A ideia de escrever um diário é resultado dessas características do personagem, o que descobrimos na primeira página do diário, na Feuillet sans date ${ }^{11}$ :

Le mieux serait d'écrire les événements au jour le jour. Tenir un journal pour y 
voir clair. Ne pas laisser échapper les nuances, les petits faits, même s'ils n'ont l'air de rien, et surtou les classer. Il faut dire comment je vois cette table, la rue, les gens, mon paquet de tabac, puisque c'est cela qui a changé. Il faut déterminer exactement l'étendue et la nature de ce changement. Par exemple, voici un étui de carton qui contient ma bouteille d'encre. Il faudrait essayer de dire comment je le voyais avant et comment à présent je le * Eh bien! c'est un parallélépipède rectangle, il se détache sur - c'est idiot, il n'y a rien à en dire. Voilà ce qu'il faut éviter, il ne faut pas mettre de l'étrange où il n'y a rien. Je pense que c'est le danger si l'on tient un journal: on s'exagère tout, on est aux aguets, on force continuellement la vérité. [...] Je dois être toujours prêt, sinon elle me glisserait encontre entre les doigts. Il ne faut rien** mais noter soigneusement et dans le plus grand détail tout ce qui se produit. Naturellement je ne peux plus rien écrire de net sur ces histoires de samedi et d'avant-hier, j'en suis déjà trop éloigné; ce que je peux dire seulement, c'est que, ni dans l'un ni dans l'autre cas, il n'y a rien eu de ce qu'on appelle à l'ordinaire un événement. Samedi les gamins jouaint aux ricochets et je voulais lancer, comme eux, un caillou dans la mer. À ce moment-là, je me suis arrêté, j'ai laissé tomber le caillou et je suis parti. Je devais avoir l'air égaré, probablement, puisque les gamins ont ri derrière mon dos. [...] Il y avait quelque chose que j'ai vu et qui m'a dégoûté, mais je ne sais plus si je regardais la mer ou le galet. [...] Enfin il est certain que j'ai eu peur ou quelque sentiment de ce genre. Si je savais seulement de quoi j'ai eu peur, j'aurais déjà fait un grand pas. Ce qu'il y a de curieux, c'est que je ne suis pas du tout disposé à me croire fou, je vois même avec évidence que je le suis pas: tous ces changements concernent les objets. Au moins c'est ce dont je voudrais être sûr. (Na, pp. 5-6).

Desde o início do livro vemos Roquentin em busca de resolução de um problema causado por situações ordinárias que alteraram toda a disposição, a significação e o sentido do mundo a sua volta e também de si mesmo. No sábado anterior ao começo da escrita, Roquentin foi alvo de deboche de uns garotos que atiravam pedras no lago para vê-las ricochetear; quando o protagonista tentou reproduzir a ação, lançou a pedra sem entusiasmo, que caiu desajeitada. Alguns dias depois, tudo ficou ainda mais complicado: uma série de coincidências e quiproquós inexplicáveis despertaram confusos sentimentos. Talvez uma crise de loucura, um certo medo ou outro sentimento semelhante, pensa Roquentin. E decide anotar o que lhe acontece, o que lhe acomete para que possa estudar-se, analisar-se. O seu ser está em questão, algo promoveu a mudança no modo como as coisas se mostravam ou em como o protagonista as percebia. A escrita do diário é deflagrada depois de uma alteração fundamental e registrar os acontecimentos para compreender esse fenômeno e suas implicações é o objetivo do personagem ao manter um diário das suas verdades e sensações. A Folha sem data é praticamente uma Introdução na qual identificamos facilmente os elementos de uma pesquisa do tipo acadêmica: a) o problema: algo alterou a figura do mundo, Roquentin percebia o mundo circundante antes de maneira diferente que percebe agora, algo cujos traços não são claros aconteceu e provocou sentimentos estranhos; b) os objetivos: determinar exatamente a extensão e a natureza da mudança percebida, se a mudança se deu em si ou no mundo; c) a justificativa: sente medo ou qualquer outro tipo de sentimento do gênero, porém não compreende do que pode estar sentindo medo ou isso que experimenta; d) os desafios: não permitir que nunces, pequenos fatos, coisas aparentemente insignificantes passem despercebidos, por outro lado, é importante ter o cuidado de não exagerar: não achar estranho o que não tem estranheza nenhuma e evitar a má consciência e reflexão cúmplice ${ }^{12}$; e) o método: contar os acontecimentos do diaa-dia, manter um diário para analisá-los claramente; e f) a hipótese: crise de loucura, ainda que não se sinta inclinado a acreditar-se louco, é preciso descobrir o que se passa para afirmar ou refutar a hipótese. 
Roquentin abandona a folha sem data sem concluí-la e interrompe o projeto, provavelmente por sentir-se "curado" depois de alguns momentos se analisando. O diário é retomado nos dias seguintes e Roquentin não interrompe o processo de escrita. O tom é mais sólido, a investigação continua, o personagem decide resolver o problema e persegue na investigação de si mesmo anotando e avaliando o mundo a sua volta e suas vivências particulares acerca dos acontecimentos. Com o desenvolver da pesquisa, Roquentin descobrirá uma verdade metafísica: a contingência.

\section{O ESSENCIAL É A CONTINGÊNCIA}

A escrita do diário é retomada e Roquentin afirma que algo muito grave lhe aconteceu e tudo foi alterado, que foi ele quem mudou ou tudo ao seu redor. E preciso compreender. Algo que se instalou sorrateiramente, à maneira de uma doença, que vem e que vai, reaparece e some e existe no corpo:

Dans mes mains, par exemple, il y a quelque chose de neuf, une certaine façon de prendre la fourchette [...]. [...] je sentais dans ma main un objet froid qui retenait mon attention par une sorte de personnalité. J'ai ouvert la main, j'ai regardé : je tenais tout simplement le loquet de la porte. Ce matin, à la Bibliothèque, quand l'Autodidacte est venu me dire bonjour, [...] il y a avait sa main, comme un gros ver blanc dans ma main. Je l'ai lâchée aussitôt et le bras est retombé mollement. [...] Donc il s'est produit un changement, pendant ces dernières semaines. Mais où ? C'est un changement abstrait qui ne se pose sur rien. Est-ce que moi qui ai changé ? Si ce n'est pas moi, alors c'est cette chambre, cette ville, cette nature; il faut choisir. (Na, pp. 8-9).

Algo novo aconteceu a Roquentin e alterou a percepção do mundo exterior e a relação consigo próprio. Algo incômodo, desconhecido, que provocou uma série de pequenas metamorfoses que se acumularam até acontecer uma verdadeira revolução e alterar todos os aspectos da vida de Roquentin. As mãos de Roquentin fazem existir a náusea que ainda não apareceu no texto como palavra e conceito, mas é sentida, experimentada corporalmente. Sem adentrar nas críticas dirigidas a Sartre sobre o tema do corpo e da corporeidade ${ }^{13}$, antevemos que não é sem cometer injustiça a acusação de cartesianismo dualista e de esquecimento do corpo. Eu sou meu corpo ${ }^{14}$, dirá Sartre em L'être et le néant, concepção que não parece opor-se à de La nausée. É importante observar, com efeito, que a nova atitude de Roquentin em relação ao mundo e aos outros, as novas sensações e sentidos que advêm dessa mudança de perspectiva são narradas como intimamente ligadas à experiência corpórea, sem a desconexão entre corpo e consciência. Um changement se produziu nas últimas semanas, Roquentin decide retomar a escrita do diário para compreender onde as mudanças aconteceram: em si ou no mundo.

A tarefa não é simples e o desafio de não ceder à reflexão cúmplice e à má-fé se mostram, já no segundo dia, como obstáculo difícil de superar:

C'est curieux : je viens de remplir dix pages et je n'ai pas dit la vérité - du moins pas toute la vérité. Quand j'écrivais, sous la date, 'Rien de nouveau', c'était avec une mauvaise conscience [...]. 'Rien de nouveau'. J'admire comme on peut mentir en mettant la raison de son côté. Évidemment, il ne s'est rien produit de nouveau, si l'on veut : ce matin, à huit heures et quart, comme je sortais de l'hôtel Printania pour me rendre à la Bibliothèque, j'ai voulu et je n'ai pas pu ramasser un papier qui traînait par terre. C'est tout et ce n'est même pas un événement. Oui, mais pour dire toute la vérité, j'en ai été profondément impressionné : j'ai pensé que je n'étais plus libre. ( $\mathrm{Na}, \mathrm{p} .14)$. 
Ainda que Roquentin tenha decidido organizar o diário e registrar os acontecimentos de maneira honesta e sincera para compreender a natureza e a extensão das mudanças que lhe acometem, as atitudes de má-fé e de reflexão cúmplice o acompanham até bom tempo da escrita, o que mostra como é anterior, mais natural e usual esse tipo de projeto e que é preciso um novo tipo de atitude diante de si para que a tarefa de examinar-se sem parcialidade tenha êxito ${ }^{15}$. Roquentin escreve uma dezena de páginas para justificar que não havia nada de novo apesar de haver algo extremamente relevante: a sensação da ausência de liberdade. Em geral, os personagens da ficção sartriana usam de má-fé para negar a própria liberdade e responsabilidade, curiosamente, Roquentin usa de mauvaise conscience para negar a sensação de ausência de liberdade que um acontecimento ordinário despertou.

A mudança de consciência de má-fé para a consciência verdadeira, para a consciência de análise e exame de si permitiu, então, prosseguir corretamente com o processo e reavaliar o que se lhe havia passado. Roquentin realiza, assim, uma descoberta sobre os objetos do mundo: "Les objets, cela ne devrait pas toucher, puisque cela ne vit pas. On s'en sert, on les remet en place, on vit au milieu d'eux : ils sont utiles, rien de plus. Et moi, ils me touchent, c'est insupportable. J'ai peur d'entrer en contact avec eux tout comme s'ils étaient des bêtes vivantes" ( $\mathrm{Na}, \mathrm{p}$. 16). Roquentin se espanta com a confusão de que os objetos, as coisas, os utensílios, possam tocá-lo. Tocar é qualidade do que é vivo, do que não é em-si, mas depois que perdeu a sensação de ser livre, os objetos parecem querer tocá-lo. A natureza do ser-em-si será tema da Introdução de L'être et le néant, Sartre define a terceira característica do ser-em-si como aquilo que é:

Cela signifie que l'être ne peut être ni dérivé du possible, ni ramené au nécessaire. La nécessité concerne la liaison des propositions idéales mais non celle des existants. [...] C'est ce qu'on appelle la contingence de l'être-en-soi. [...] L'êtreen-soi n'est jamais ni possible ni impossible, il est. C'est ce que la conscience exprimera [...] en disant qu'il est de trop [...]. Incrée, sans raison d'être, sans rapport aucun avec un autre être, l'être-en-soi est de trop pour l'éternité. (SARTRE, 1943, p. 33)

Os objetos são contingentes, são de trop, são excedentes, contingentes para toda a eternidade. A sensação de que os objetos tocam, característica exclusiva do Para-si, levará Roquentin à descoberta da sua própria contingência. No ensaio de ontologia fenomenológica, confirmamos o uso do método que parte dos "fenômenos", do que aparece: 'L'être est. L'être est en soi. L'être est ce qu'il est. [...] Ainsi, nous sommes parti des 'apparitions' et nous avons été conduit progressivement à poser deux types d'être : l'en-soi et le pour-soi [...]" (SARTRE, 1943, p. 33). Esses dois tipos de ser são incomunicáveis e absolutamente cindidos, não realizam jamais uma síntese: por isso, o espanto de Roquentin ao perceber características do Para-si, o tocar, no Em-si. O ser é; somente o homem existe. O toque é característica da realidade humana e não das coisas, dos objeto. O exame limpo, claro e honesto que Roquentin passa a fazer depois da sua atitude de mauvaise conscience o farão lembrar-se melhor do episódio que provocou as mudanças. Ainda no mesmo dia, prosseguindo com a narrativa, temos:

Maintenant je vois ; je me rappelle mieux ce que j'ai senti, l'autre jour, au bord de la mer, quand je tenais ce galet. C'était une espèce d'écoeurement douceâtre. Que c'était donc désagréable! Et cela venait du galet, j'en suis sûr, cela passait du galet dans mes mains. Oui, c'est cela, c'est bien cela: une sorte de nausée dans les mains. (Na, p. 16).

Uma espécie de écourement douceâtre que passou da pedra para as mãos: um tipo de náusea nas mãos. A apreensão da existência fática e contingente, do corpo, do ego em meio ao mundo, entre as coisas se dá na forma de náusea, na forma da 
apreensão afetiva e sensível da náusea nas mãos de Roquentin. É a primeira vez em que Roquentin nomeia essa disposição fundamental de náusea. É nesse mesmo momento de descoberta do seu existir como corpo entre corpos, da sua existência fática e, como consequência, da sua contingência e gratuidade, que Roquentin experiencia a náusea, que não o deixará mais. A náusea descrita por Roquentin é a revelação do corpo à consciência que se percebe em meio a outros em-si. A experiência da força das coisas, da facticidade, da contingência é, ao mesmo tempo, a vivência desvelada da situação e de como o mundo condiciona Roquentin. Ele não pode ramasser le papier, mas não é por isso que não é livre, o que acontece é que liberdade não é ultrapassar a resistência oferecida pelo mundo. A náusea narrada por Sartre-Roquentin é a apreensão pela consciência de si como existência de fato, é Roquentin se captando nova e repetidamente na sua totalidade sensível. E essa náusea insuperável revela o corpo à consciência: para aplacá-la é possível buscar refúgio na dor física ou no prazer, mas tanto um quanto o outro existem pela consciência o que, no limite, significa a manifestação irremediável da corporeidade e, ainda, da náusea: "il peut arriver que nous recherchions l'agréable ou la douleur physique pour nous en délivrer, mais dès que la douleur ou l'agréable sont excités par la conscience, ils manifestent à leur tour sa facticité et sa contingence et c'est sur fond de nausée qu'ils se dévoilent" (SARTRE, 1943, p. 404). A náusea não vem das coisas, mas disso que na relação com as coisas se mostra como ameaça de dissolução do ser-para-si em ser-em-si ${ }^{16}$. A náusea invade a consciência no confronto com as coisas e suas qualidades na medida em não revelam mais que uma carne sem mundo.

Muitas páginas adiante, Roquentin faz a grande descoberta da existência, a compreensão da náusea, a iluminação da experiência da contingência. São quase 50 páginas do que se passa em alguns dias (Na, pp. 113-160) e eu não poderia sequer selecionar os excertos mais importantes, uma vez que cada linha guarda uma preciosidade teórica que permitiria páginas de argumentações e debates, sem o risco severo de sempre escapar ainda tramas e objetos de discussão. Apenas apontarei alguns trechos para conduzir o desenvolvimento deste trabalho, mas recomendo fortemente a leitura completa do romance, sobretudo destas páginas.

A relevância do passado sobre o presente e da temporalidade em relação à consciência e ao mundo é tema das páginas iniciais desta segunda-feira de descobertas: "Comment donc, moi qui n'ai pas eu la force de retenir mon propre passé, puis-je espérer que je sauverai celui d'un autre?" (Na, p. 113). Roquentin abandona, então, seu trabalho sobre M. de Rollebon ${ }^{17}$. Em seguida, Roquentin se questiona sobre o que fazer a partir de agora. $\mathrm{O}$ seu projeto de vida foi abandonado, as perguntas sobre o que fazer agora somam-se e a existência, como corpo, como consciência, como uma coisa unida é descoberta:

La Chose, qui attendait, s'est alertée, elle a fondu sur moi, elle se coule en moi. L'existence, libérée, dégagée, reflue sur moi. J'existe. J'existe. C'est doux, si doux, si lent. Et léger : on dirait que ça tient en l'air tout seul. Ça remue. [...] Et cette mare, c'est moi. Et la langue. Et la gorge, c'est moi. Je vois ma main, qui s'épanouit sur la table. Elle vit - c'est moi. (Na, pp. 117-118).

A mão que antes aparecia como objeto, como animal (crabe), agora não é nada além da mão que vive, abre e fecha os dedos. A descoberta da existência também se dá pela via dos pensamentos e da linguagem:

Les pensées, c'est ce qu'il y a de plus fade. Plus fade encore que de la chair. Ça s'étire à n'en plus finir et ça laisse un drôle de goût. Et puis il y a des mots, audedans des pensées, les mots inachevés, les ébauches de phrase qui reviennent tout le temps [...]. Par exemple, cette espèce de rumination douloureuse : j'existe, c'est moi qui l'entretiens. Moi. [...] Mais la pensée, c'est moi qui la continue, qui 
la déroule. J'existe. Je pense que j'existe. [...] Si je pouvais m'empêcher de penser! J'essaie, je réussis [...]. Je ne veux pas penser... Je pense que je ne veux pas penser. Il ne faut pas que je pense que je ne veux pas penser. Parce que c'est encore une pensée. On n'en finira donc jamais ? Ma pensée c'est moi : voilà pourquoi je ne peux pas m'arrêter. J'existe parce que je pense... ( $\mathrm{Na}, \mathrm{pp} .118$ 119).

Pensar é ter consciência de pensar, logo consciência de existir. Os pensamentos que o desagradam, como a tomada de consciência de existir, são, por sua vez, maneiras de existir, modos de lançar-se na direção exata da existência e não há caminho possível de desvio. Os pensamentos, as reflexões nascem como uma vertigem, como uma sensação de horror à existência, como um atordoamento diante da impossibilidade de não-existir e afirmam e renovam a sensação de existir.

Algumas páginas adiante, na mais famosa cena do romance: no jardim público, sentado no banco sob uma grande castanheira, Sartre narra a descoberta:

Je voudrais tant me laisser aller, m'oublier, dormir. Mais je ne peux pas, je suffoque : l'existence me pénètre de partout, par les yeux, par le nez, par la bouche... Et tout d'un coup, le voile se déchire, j'ai compris, j'ai $v u$. [...] Je ne peux pas dire que je me sente allégé ni content ; au contraire, ça m'écrase. Seulement mon but est atteint : je sais ce que je voulais savoir; tout ce qui m'est arrivé depuis le mois de janvier, je l'ai compris. La Nausée ne m'a pas quitté et je ne crois pas qu'elle me quittera de sitôt ; mais je ne la subis plus, ce n'est plus une maladie ni une quinte passagère : c'est moi. [...] J'étais assis, un peu voûté, la tête basse, seul em face de cette masse noire et noueuse, entièrement brute et qui me faisait peur. Et puis j'ai eu cette illumination. [...] Jamais, avant ces derniers jours, je n'avais pressenti ce que voulait dire "exister". [...] à l'oridinaire l'existence se cache. Elle est là, autour de nous, en nous, elle est nous, on ne peut pas dire deux mots sans parler d'elle et, finalement, on ne la touche pas. [...] Et puis voilà, tout d'un coup, c'était là, c'était clair comme le jour : l'existence s'était soudain dévoilée. [...] Nous étions un tas d'existants gênés, embarrassés de nous-mêmes, nous n'avions pas la moindre raison d'être là, ni les uns ni les autres, chaque existant, confus, vaguement inquiet, se sentait de trop par rapport aux autres. De trop : c'était le seul rapport que je pusse établir entre ces arbres, ces grilles, ces cailloux. [...] Et moi - veule, alangui, obscène, digérant, ballottant de mornes pensées - moi aussi j'étais de trop. [...] Et la chair rongée eût été de trop dans la terre qui l'eût reçue et mes os enfin, nettoyés, écorcés, propres et nets comme des dents eussent encore été de trop : j'étais de trop pour l'éternité. [...] Et sans rien formuler nettement, je comprenais que j'avais trouvé la clé de l'Existence, la clé de mes Nausées, de ma propre vie. De fait, tout ce que j'ai pu saisir ensuite se ramène à cette absurdité fondamentale. Absurdité : encore un mot ; je me débats contre des mots [...]. Absurde : par rapport aux cailloux, aux touffes d'herbe jaune, à la boue sèche, à l'arbre, au ciel, aux bancs verts. $\mathrm{Na}, \mathrm{p}$. $149-153$

A narração da descoberta da existência contingente, do ser de trop se assemelha ao recorte exposto acima da Introdução à L'être et le néant sobre a natureza do em-si. Inclusive as palavras são as mesmas: de trop pour l'éternité em ambos os livros. Em L'être et le néant Sartre se refere à terceira propriedade essencial do ser-em-si, a de ser o que é; em La nausée, à dimensão fática da existência do ser-para-si. A impossibilidade de deixar de existir sendo, de esquecer-se depois da tomada de consciência, depois do despertar para o apelo do ser. Roquentin não pode mais esquecer-se ou deixar-se simplesmente seguir no fluxo dos acontecimentos, alienado e desacordado, ao menos não sem saber que o faz de maneira deliberada e consciente, tentando parecer que agia como antes. Mas nada mais é como antes porque "a 
existência penetra", o penso da existência deve ser carregado e agora cada decisão depende de si, da sua escolha, da sua deliberação. A náusea é a descoberta de que nada vem senão por meio de si mesmo, que se abandona ou continua a pesquisa sobre o Marquês de Rollebon, se deixa ou continua em Bouville, se vai ou não ao encontro de Anny, são escolhas, ações cuja origem é ele próprio e que se escolhe permanecer não parte, se vê Anny não vê outros, ou seja, Roquentin descobre que a existência precede a essência, que é livre e responsável pelo seu engajamento no mundo. Roquentin descobre o que é existir: que não há sentido prévio para a vida, que não há a quem ou a que agarrar-se, que sua liberdade é absoluta tanto quanto a responsabilidade pelo que fizer de si e que não há salvação para a contingência. $O$ protagonista observa que a existência sempre esteve lá, mas de modo velado, escondido, é preciso uma mudança de perspectiva, uma alteração na visada para aperceber-se do sentido e da significação que a contingência da existência e da liberdade têm. A atitude natural, a maneira usual de relacionar-se com o mundo, dirigir-se ao mundo, não é a fenomenológica, não é a de buscar compreender as estruturas e as condições de possibilidade da ação e do sentido; por isso, no caso de Roquentin, algo aconteceu e alterou o curso das suas ações e projetos. A náusea diante do absurdo da existência o colocou diante da radicalidade fundamental da existência. Compreendendo o que se passou no Jardim Público, debaixo da castanheira, Roquentin pode colocar em palavras:

Ce moment fut extraoridinaire. J'étais là, immobile et glacé, plongé dans une extase horrible. Mais, au sein même de cette extase quelque chose de neuf venait d'apparaître ; je comprenais la Nausée, je la possedais. À vrai dire je ne me formulais pas mes découvertes. Mais je crois qu'à présent il me serait facile de les mettre en mots. L'essentiel c'est la contingence. Je veux dire que, par définition, l'existence n'est pas la nécessité. Exister, c'est être là, simplement ; les existants apparaissent, se laissent rencontrer, mais on ne peut jamais les déduire. [...] Or aucun être nécessaire ne peut expliquer l'existence : la contingence n'est pas un faux-semblant, une apparence qu'on peut dissiper ; c'est l'absolu, par conséquent la gratuité parfaite. Tout est gratuite, ce jardin, cette ville et moi-même. (Na, p. 155).

O extraordinário momento da compreensão do que se passou nos últimos meses não atenua nem simplifica o peso da descoberta: a náusea é a descoberta de si como existência contingente. A ambiguidade dessa descoberta reside no fato de que a liberdade suprime todas as obrigações metafísicas ao passo que impõe sobre o sujeito o peso da responsabilidade sobre si, o mundo e os outros. A questão sobre o que fazer de si se coloca como a questão fundamental para a realidade humana: a criação, a reafirmação dos projetos, o abandono de projetos anteriores, são possibilidades que se fazem presentes constantemente, engajando o Para-si nessa ordem temporal da historicidade e exigindo escolha contínua diante da contingência e da facticidade da liberdade.

\section{Considerações finais: Ser e EXISTIR}

La nausée é uma obra complexa e teoricamente rica, ao mesmo tempo incarna e ironiza o projeto moral de salvação da contingência por meio das aventuras perseguidas por Roquentin, da vontade de deixar algo grandioso para a posteridade, como a pesquisa sobre a vida do Marquês de Rollebon, da arte, da música da cantora e do compositor ao final do romance. Segundo Contat e Rybalka, antes mesmo de La nausée ser publicada o conteúdo da obra já não correspondia mais totalmente ao pensamento de Sartre ${ }^{18}$.

É impossível escapar à liberdade, Roquentin não consegue deixar-se ir, deixar de 
ser, deixar de existir, pois estamos condenados à liberdade. A contingência e o absurdo da existência fazem com que nada exija esta ação, o que nos faz totalmente responsáveis por ela. A ação é gratuita, contingente, sem importância ou relevância, mas é preciso agir, ou seja, não há porquê esta determinada ação acontecer, mas é necessária enquanto tendo fundamento para acontecer. Sartre narra um Roquentin destacado da massa, espécie de homem solitário ao mesmo tempo em razão da iluminação que sua consciência tem em relação à existência, à contingência e à gratuidade da existência e da condenação que isso representa em relação à vida em coletividade.

Roquentin é a figura do homme seul formulada por Sartre durante sua juventude. Ao contrário do que muitos se esforçam em mostrar, a ideia de homme seul ${ }^{19}$ não é o resultado intelectual de um completo desengajamento. $\mathrm{O}$ homem solitário da década de 20 e início dos anos 30 representou uma forma de engajamento particular do tipo resistente contra o burguês típico dos anos ' 30 e a sociedade moralista tradicional:

En sortant de Normale, j'ai écrit une pièce. Elle s'intitulait Epiméthée. Son héros était le frère de Prométhée. Ça se passait dans les cieux. Epiméthée personnifiait ce que j'appelais alors "homme seul" et que je distinguais de l'aristocrate, de l'être qui prétend à l'élite (celui-là, je le méprisais tout à fait). "L'homme seul", lui, est quelqu'un qui n'est pas attiré par la civilisation et qui se dote, de ce fait, d'une manière de penser différente de la manière humaine. (DORT, 1990, p. 875).

Até a chegada da Segunda Guerra Mundial e a mobilização de Sartre, o principal rival do filósofo era a visão de mundo burguesa, moralista, elitista e clássica da qual ele próprio era fruto. Sartre rejeitava a perspectiva burguesa, que era tão imponente à época que mesmo uma das mais incisivas correntes surgidas como alternativa à visão clássica e tradicional veio da própria burguesia e se manteve ainda elitista e individualista: o surrealismo. La nausée, junto com Le mur, L'écrits de jeunesse, representa a tentativa sartriana de, se não demolir, ao menos resistir à perspectiva dominante de mundo. Sem ter ainda uma alternativa realmente viável à perspectiva burguesa nesse momento, Sartre escreve a partir da concepção de homme seul, ideia que perdurará por alguns anos e aparecerá ainda durante a guerra, principalmente, nos personagens de Bariona, Orestes e Mathieu. Apesar das ambiguidades do texto, em relação às intenções e possibilidades de escapar da contingência via criação, via arte, via literatura ou pela via da aventura, La nausée marca o fim de um período, o do homme seul ${ }^{20}$.

O conjunto de La nausée conta a aventura de Roquentin entre as coisas, entre os objetos, no mundo a sua volta; todavia, a conhecemos pela perspectiva do sujeito, do protagonista. Ainda que Roquentin se perca no meio do mundo e seja só mais no meio de outros, a sua consciência permanece central em torno da qual todo o texto e toda a narrativa se organizam, o que nos remete à epígrafe de Louis-Ferdinand Céline: "C'est un garçon sans importante collective, c'est tout juste un individu". Roquentin não é somente $u m$ indivíduo sem importância, ele é $o$ indivíduo que permite à coletividade experimentar conjuntamente a aventura da existência e conhecer a diferença entre ser e existir.

Em La nausée, Sartre entende a existência reduzida ao ser aí, estar aí (être là ${ }^{21}$ ): "Exister, c'est être là, simplement" (Na, p. 155), no sentido mais material, corpóreo e fático. Em lugar de explicar teoricamente por meio de termos abstratos e metafísicos ${ }^{22} \mathrm{o}$ que é a existência, Sartre faz da experiênca metafísica um romance recheado de expressões animalescas e metáforas bastante concretas, abusando de referências físicas e pútreas. $\mathrm{O}$ autor descreve a descoberta da existência por expressões como: pequenas bestas sinistras, serpente morta, doença, corpos em decomposição e outras figuras do viscoso bastante preenchidas de significação.

Em La nausée, Sartre faz uso de determinadas imagens, notadamente as elencadas acima e outras de igual gênero de repugnância, viscosidade e natureza 
fisiológica, para referir-se à existência. Em obras posteriores, de literatura também, mas sobretudo em L'être et le néant, as mesmas imagens designam o ser. E esta parece ser a principal questão que poderíamos examinar para concluirmos o presente escrito, uma vez que filosoficamente a grande questão de Sartre é a relação entre o Ser e o Nada, como sugere o título da sua obra magna.

Em La nausée, Sartre parece opor existência a ser, em que temos o ser referindose ao homem e existência como o modo de ser das coisas. Roquentin descobre que seu modo de ser é o da facticidade, da gratuidade, da contingência, o mesmo modo de ser das coisas. Em L'être et le néant, em lugar de identificar facticidade à existência, como fez no romance, Sartre atribui a facticidade como característica do ser. O elemento da transcendência como possibilidade de ultrapassar o mundo das coisas, a materialidade, que em La nausée é vinculado ao ser, será característica da existência. O ser, em L'être et le néant, significa justamente aquilo sobre o que o movimento da transcendência pode projetar-se. A existência, portanto, toma o sentido de transcendência do ser.

Podemos compreender, então, se fizermos as devidas relações e pontes, que o sentido de existência de L'être et le néant está relacionado ao sentido de ser de $L a$ nausée. Aqui, ser designa o movimento de transcendência da facticidade, a tentativa de salvação pela arte, de justificação da vida; em L'être et le néant, o termo equivalente a esse movimento, a esse tipo de projeto - se é que ele é possível - é o de existência. Existir é a tomada de consciência do Para-si da sua contingência e o movimento pelo qual transcende o ser, a situação, o mundo, a matéria, a facticidade (o em-si). A grande questão para analisar nas obras ficcionais posteriores é se é possível justificar a existência, ou, se preferir, de que maneira podemos dar sentido à vida?

\section{REFERÊNCIAS}

ASTRUC, A.; CONTAT, M. Sartre. Un film réalisé par Alexandre Astruc et Michel Contat. Texte intégral. Paris: Gallimard, 1977.

BEAUVOIR, S. de. La force de l'âge. Paris : Gallimard, 1960.

CAMUS, Albert. « Le Mur » de Jean-Paul Sartre. In : Alger Republicain, 12 mars 1939, pp. 4952.

CONTAT, Michel; RYBALKA, Michel. Les écrits de Sartre. Paris : Gallimard, 1970.

CONTAT, Michel; RYBALKA, Michel. " Extraits inédits du film 'Sartre par lui-même' ». In: SARTRE, Jean-Paul. Oeuvres romanesques. Pléiade. Paris: Gallimard, 1981.

DORT, Bernard. « Entretien avec Sartre ». In : Les temps modernes, n. ${ }^{\circ} 531-532,2,1990$, pp. 872-889.

IDT, Genevieve. La nausée : Sartre, analyse critique. Paris : Hatier, 1971.

IDT, Genevieve. "L'emergence du 'phenomene Sartre' », de la publication du « Mur » (juillet 1937) a l'attribution du prix populiste (avril 1940) ». In : GALSTER, Ingrid (Dir.). La naissance du "Phénomène Sartre ». Raisons d'un succes 1938-1945. Seuil : Paris, 2001, pp. 47-85.

SARTRE, Jean-Paul. L'être et le néant. Essai d'ontologie phenomenologique. Paris : Gallimard, 1943.

SARTRE, Jean-Paul. OEuvres romanesques. Dir. Michel Contat. Bibliotheque de la Pleiade. Paris : Gallimard, 1981.

\section{Notas}

$1 \mathrm{O}$ presente texto é a versão na forma de artigo científico do Minicurso apresentado no XXIV Simpósio de Filosofia Moderna e Contemporânea realizado na Universidade Estadual do Oeste do Paraná, na cidade de Toledo/PR. Agradecimentos pelo convite, tanto do minicurso quanto da publicação, ao Professor Dr. Claudinei Freitas da Silva. 
2 Reconstruo o resumo da gênese de La nausée a partir dos relatos de Simone de Beauvoir em La force de l'âge; de entrevistas de Sartre e dos seus textos autobiográficos La drôle de guerre e Les mots; além dos trabalhos acadêmicos de Idt (1971), Contat e Rybalka (1970; 1981).

3 "Sartre a vingt-six ans quand, au cours de l'automne 1931, il commence un ouvrage qu'il appelle son 'factum sur la contingence' et qui deviendra La nausée" (CONTAT E RYBALKA, 1981, p. 1659).

4 A revista editada era NRF - La Nouvelle Revue Française.

5 "Cela suffit pour qu'on aime la Nausée comme le premier appel d'un esprit singulier et vigoureux dont nous attendons avec impatience les œuvres et les leçons à venir" (CAMUS, 1939, p. 50).

6 “[...] c'est en regardant passer des images sur un écran qu'il avait eu la révélation de la nécessité de l'art et qu'il avait découvert, par contraste, la déplorable contingence des choses données" (BEAUVOIR, 1960, p. 53).

7 Em 1931, Sartre publica o discurso L'art cinématographique. Disponível em: Contat e Rybalka, 1970, pp.546-552.

8 Declaração realizada em 1972, publicada no livro e exibida no filme de Astruc e Contat: Sartre: un film réalisé par A. Astruc e M. Contat; utilizo aqui a versão integral publicada em livro.

9 HILGERT, L. H. Ontologia e moral na obra ficcional de Sartre. (Tese de Doutorado) Unicamp. - Campinas, SP, 2017.

10 HILGERT, L. H. "Questões de método: filosofia e literatura em Sartre". Analytica, Rio de Janeiro, v. 22, n. 1, 2018, pp. 221-246.

11 Uso a versão de La nausée disponível na coleção da Pléiade (1981) das obras completas de Sartre. Daqui em diante, Na.

12 Sartre fala em mauvaise conscience, como veremos adiante, como a possibilidade de mentir colocando a razão do nosso lado, ideia que se assemelha aos conceitos de má-fé e de reflexão cúmplice.

13 Preparo artigo que será publicado em breve sobre o tema do corpo nas obras ficcionais de Sartre. Convido as interessadas e os interessados no tema a aguardarem a divulgação do periódico.

14 “[...] je suis mon corps dans la mesure où je suis [...]”. (SARTRE, 1943, p. 366).

15 Poderíamos falar aqui de atitude natural versus atitude fenomenológica, mas a averiguação desta hipótese nos levaria a extrapolar os objetivos do presente texto.

16 É por isso que a metáfora do viscoso é recorrente nos escritos de Sartre e associado à ameaça da dissolução do para-si em em-si. Em linhas muito gerais, a viscosidade será tratada na obra L'être et le néant como uma metáfora devido ao seu estado indefinido que tem a fluidez do líquido e a dureza do sólido mesmo estando entre um e outro e não sendo nem um nem outro. Normalmente, o líquido, a dinamicidade, a fluidez, dizem respeito ao domínio do para-si pela sua própria característica de indeterminado, fugidio, transparente; enquanto o sólido, o duro, remetem à opacidade impenetrável do em-si; o visqueux é o líquido em vias de solidificação ou o sólido em curso de liquidificação e simbolizará, portanto, a contaminação do para-si pelo em-si: "[...] il représente en lui-même un triomphe naissant du solide sur le liquide, c'est-à-dire une tendance de l'en-soi d'indifférence, que représente le pur solide, à figer la liquidité, c'est-à-dire à absorber le pour-soi qui devrait le fonder" (SARTRE, 1943, pp. 653-654). Seguidamente Sartre demonstra um horror ao viscoso: "C'est la crainte non de la mort, non de l'en-soi pur, non du néant, mais d'un type d'être particulier, qui n'existe pas plus que l'en-soi-pour-soi et qui est seulement représenté par le visqueux" (SARTRE, 1943, p. 657).

17 Não tratarei deste tema aqui. Ver: Idt, 1971, pp. 28-38.

18 Cf. Contat e Rybalka, 1971, p. 63.

19 Exploro melhor essa ideia na minha tese de doutorado, aqui recapitulo alguns tópicos já tratados lá.

20 É o que primeiro afirmaram Contat e Rybalka, 1981, p. 1673.

21 A expressão être-là ou être là remete ao Dasein heideggeriano, porém, o contato de Sartre 
com o filósofo alemão era insipiente ainda durante a escrita de La nausée.

22 Importante lembrar que La nausée foi acusada de ser uma longa e abstrata meditação sobre a contingência. Cf. Beauvoir, 1960, p. 111. 